\title{
Multiple DNA Binding Modes of a Metallointercalator Revealed by DNA Film Voltammetry
}

\author{
Liang-Hong Guo, ${ }^{* \dagger}$ Ming-Yuan Wei, ${ }^{\dagger, *}$ and Hao Chen $*, \hbar$ \\ State Key Laboratory of Environmental Chemistry and Ecotoxicology, Research Center for Eco-environmental \\ Sciences, Chinese Academy of Sciences, P. O. Box 2871, 18 Shuangqing Road, Beijing 100085, China, and \\ Department of Chemistry, College of Natural Sciences, Huazhong Agricultural University, Wuhan, Hubei \\ 430070, China
}

Received: April 4, 2006; In Final Form: August 3, 2006

\begin{abstract}
Binding and the redox reaction of the metallointercalator $\mathrm{Ru}(\mathrm{bpy})_{2}(\mathrm{dppz})^{2+}\left(\mathrm{bpy}=2,2^{\prime}\right.$-bipyridine, $\mathrm{dppz}=$ dipyrido[3,2-a:2',3'-c]phenazine) with DNA was investigated by DNA film voltammetry. Calf-thymus DNA (CT-DNA) was assembled on a tin-doped indium oxide electrode by layer-by-layer electrostatic adsorption. Voltammetry of $\mathrm{Ru}(\mathrm{bpy})_{2}(\mathrm{dppz})^{2+}$ (Ru-dppz) bound to the DNA film was measured in a redox-free electrolyte and showed strong dependence on the concentration of the metallointercalator. At low Ru-dppz concentrations, a single oxidation peak was observed, the potential of which shifted from 1.25 to $1.1 \mathrm{~V}$ with increasing Ru-dppz concentration (peak 1). At high metal chelate concentrations, an additional oxidation peak emerged with a potential of $1.25 \mathrm{~V}$ which was unaffected by the Ru-dppz concentration (peak 2). Three experiments were performed to investigate the mechanism and structural basis of the multiple peaks. First, voltammetry of Os(bpy $)_{2}(\mathrm{dppz})^{2+}$ bound to the CT-DNA film displayed only one peak at its oxidation potential of about $0.75 \mathrm{~V}$. Second, the concentration dependence of Ru-dppz bound to a poly-(AU) film (which does not contain any guanine bases) exhibited only one oxidation peak at about $1.22 \mathrm{~V}$ that was independent of the Ru-dppz concentration. Third, when the guanine concentration in a mixed film of CT-DNA and poly-(AU) was changed and the bound Ru-dppz was kept constant, a pre-peak emerged and shifted to $1.1 \mathrm{~V}$ with increasing guanines. Based on these results, the appearance of two peaks in the voltammetric measurements of CT-DNA was rationalized by invoking two different DNA binding modes for the Ru-dppz complex: intercalation and electrostatic association. Peak 2 arises from slow oxidation of guanines catalyzed by Ru-dppz electrostatically associated with the DNA film, since the addition of $\mathrm{Mg}^{2+}$ decreases the magnitude of peak 2. Peak 1 was not affected by $\mathrm{Mg}^{2+}$ ions, leading us to conclude that it is due to intercalated Ru-dppz. The intercalation positions the metal complex in close contact with the guanines inside DNA resulting in fast electrocatalytic reaction, giving rise to a catalytic pre-peak.
\end{abstract}

\section{Introduction}

The study on the interactions between small molecules and DNA has become increasingly important due to its implication in the regulation of gene expression by activators and repressors in vivo. Traditionally, such interactions were investigated by footprinting and affinity cleavage in combination with NMR and X-ray crystallography. ${ }^{1}$ Design and synthesis of metallointercalators of varying shape, symmetry, and functionality has enabled detailed spectroscopic investigation of both recognition and redox reaction with DNA. ${ }^{2}$ Bard's group pioneered voltammetric study of the binding interaction between metal chelates and DNA in solution. ${ }^{3}$ Using metal polypyridine complexes as redox probes, binding and redox chemistry with DNA was elucidated in detail by Thorp's group. ${ }^{4}$ More recently, the recognition of various electrostatic and intercalative binders with DNA films immobilized on electrode surfaces was investigated. ${ }^{5-9}$ The subject has also been explored by other research groups in their efforts to develop DNA electrochemical sensors. ${ }^{10-14}$

We investigated both recognition and redox chemistry of metallointercalators with DNA films assembled on electrode

* Corresponding authors.: Phone/fax: 86-10-62849685 (L.-H.G.); 8627-87282048 (H.C.). E-mail: LHGuo@mail.rcees.ac.cn (L.-H.G.); hchenhao@mail.hzau.edu.cn (H.C.).

Chinese Academy of Sciences.

$\doteqdot$ Huazhong Agricultural University. surfaces. Using such a DNA film voltammetry technique, samples of as low as a few tens of nanograms can be investigated on a conventional electrode, instead of milligram samples used in solution measurement. Because the redox probe is attached to the DNA film on an electrode surface, the resolution of the voltammetric response is substantially higher than that of solution-phase electrochemistry. This property permits separation of electrochemical processes that are close in redox potential, as illustrated in this paper. The technique possesses many of the advantages of the protein film voltammetry developed and popularized by Armstrong and coworkers. ${ }^{15}$

We report here direct observation of multiple DNA binding modes of a metallointercalator $\mathrm{Ru}(\mathrm{bpy})_{2}(\mathrm{dppz})^{2+}\left(\mathrm{bpy}=2,2^{\prime}-\right.$ bipyridine, $\operatorname{dppz}=$ dipyrido[3,2-a:2',3'-c]phenazine) by DNA film voltammetry. When bound to double-stranded DNA film on tin-doped indium oxide electrode, two distinctive oxidation peaks at 1.1 and $1.25 \mathrm{~V}$ were observed. Control experiments with $\mathrm{Ru}(\mathrm{bpy})_{2}(\mathrm{dppz})^{2+}$ on poly-(AU) and DNA/poly-(AU) films as well as Os(bpy $)_{2}(\mathrm{dppz})^{2+}$ on DNA film suggest the two peaks are associated with the oxidation of guanines catalyzed by $\mathrm{Ru}-$ dppz at different rates. The different redox reactivities of the metal complex were rationalized by a two binding mode hypothesis: one intercalative and the other electrostatic. 


\section{Experimental Methods}

Calf thymus double-stranded DNA (CT-DNA, approximately $13 \mathrm{~K}$ base pairs), poly(guanadylic acid) (5') (poly-G), poly(adenylic acid) (5') (poly-A), poly(uridylic acid) (5') (poly-U), poly(cytidylic acid) (5') (poly-C), $\mathrm{Ru}(\mathrm{bpy})_{2} \mathrm{Cl}_{2}$, and 3-mercaptopropionic acid (MPA) were obtained from Sigma-Aldrich Chemical Co. (St. Louis, MO) and used as received. Avidin was purchased from MP Biomedicals (Irvine, CA). Ru(bpy) $2^{-}$ $(\mathrm{dppz})^{2+}(\mathrm{Ru}-\mathrm{dppz})$ was synthesized according to the published procedure. ${ }^{16,17} \mathrm{Os}(\mathrm{bpy})_{2}(\mathrm{dppz})^{2+}(\mathrm{Os}-\mathrm{dppz})$ was a kind gift from Prof. H. Holden Thorp at the University of North Carolina. Solutions were prepared in high-purity water from a Millipore Milli-Q (Biocel) water purification system (Billerica, MA). Poly(AU) was obtained by hybridizing poly-A and poly-U. The two polynucleotides were dissolved in a $20 \times$ SSC solution (3 M $\mathrm{NaCl} / 0.3 \mathrm{M}$ sodium citrate, $\mathrm{pH} 7.0$ ) at a concentration of $2 \mathrm{mg} /$ $\mathrm{mL}$ each. The mixture was heated at $95{ }^{\circ} \mathrm{C}$ for $5 \mathrm{~min}$ and then cooled slowly to room temperature. The hybridized polynucleotide was diluted 10 times with $10 \mathrm{mM}$ sodium oxalate/oxalic acid ( $\mathrm{pH} \mathrm{5.5)} \mathrm{for} \mathrm{film} \mathrm{assembly.} \mathrm{The} \mathrm{concentration} \mathrm{of} \mathrm{nucleic}$ acids was determined by measuring the absorbance at $260 \mathrm{~nm}$.

Tin-doped indium oxide (ITO) conductive glass was obtained from WeiGuang Corporation (Shenzhen, Guangdong Province, People's Republic of China) and cut into $2.5 \times 0.5 \mathrm{~cm}$ electrodes. The electrodes were cleaned in an ultrasonic cleaner sequentially with each of the following solutions: household detergent in water (15 min), deionized water (2 min, twice), acetone (5 $\mathrm{min}), 2$-propanol (5 $\mathrm{min})$, and deionized water (10 min, twice). Cleaned ITO electrodes were first coated with 10 $\mu \mathrm{L}$ of avidin $(0.25 \mathrm{mg} / \mathrm{mL}$, dissolved in $20 \mathrm{mM}$ phosphate buffer, $\mathrm{pH} 7.3$ ) for $1.5 \mathrm{~h}$ and then washed carefully. This surface is denoted as ITO/avidin. The modified electrode was followed by coating with $10 \mu \mathrm{L}$ of $0.2 \mathrm{mg} / \mathrm{mL}$ nucleic acid in $10 \mathrm{mM}$ sodium oxalate/oxalic acid, $\mathrm{pH} 5.5$, for $30 \mathrm{~min}$, and is denoted as ITO/avidin/DNA. Finally, Ru-dppz was reacted with the DNA film for $30 \mathrm{~min}$, and unbound metal complex was washed off with $20 \mathrm{mM}$ phosphate (ITO/avidin/DNA/Ru-dppz).

Cyclic voltammetry was performed on a CHI 660B Electrochemistry Analyzer ( $\mathrm{CH}$ Instruments, Austin, TX) with a Pt counter electrode and an $\mathrm{Ag} / \mathrm{AgCl}$ reference electrode (also from $\mathrm{CHI})$. The electrode area in contact with the electrolyte was $0.5 \mathrm{~cm}^{2}$.

Quartz crystal microbalance (QCM) measurements were carried out on a CHI 400A instrument (Austin, TX) to monitor DNA film growth. Gold-coated quartz crystal resonators provided by $\mathrm{CHI}$ were rinsed with freshly prepared piranha solution $\left(95^{\circ} \mathrm{C}\right)$ for nearly $15 \mathrm{~min}$ and then rinsed successively with water and ethanol. (Caution! Piranha solution should be handled with extreme care, and only small volumes should be prepared at any time.) The cleaned gold electrode was coated with MPA by adsorption in a $4 \mathrm{mM}$ solution in ethanol for $1 \mathrm{~h}$ to introduce negative charges on the surface. Avidin and DNA layers were assembled following the same procedure as described above for ITO electrodes. After assembly of each layer, the surface was rinsed with water and blown dry with nitrogen before QCM measurement.

\section{Results and Discussion}

DNA films were assembled on ITO electrode surface by layer-by-layer electrostatic adsorption, using a positively charged protein, with avidin as the first layer and the nucleic acid as the second layer. QCM measurements were performed on a gold crystal to verify the immobilization of the DNA layer and to

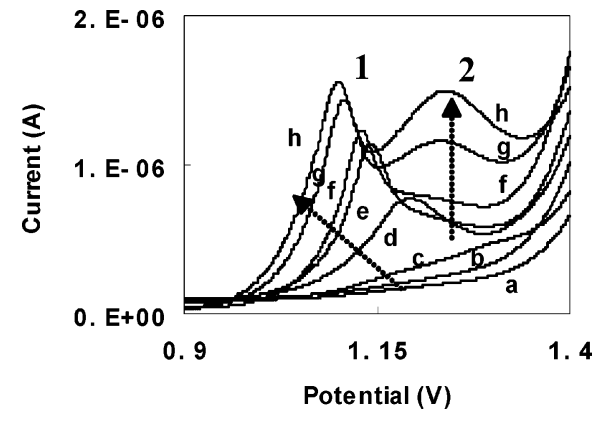

Figure 1. Voltammograms of CT-DNA film electrodes in $20 \mathrm{mM}$ phosphate buffer ( $\mathrm{pH} 7.3$ ) after reacting with (from a to h) $0,0.1,0.3$, $1,3,10,30$, and $100 \mu \mathrm{M} \mathrm{Ru}(\mathrm{bpy})_{2}$ (dppz). DNA films were deposited from a $0.2 \mathrm{mg} / \mathrm{mL}$ solution. Scan rate: $10 \mathrm{mV} / \mathrm{s}$. Reference: $3 \mathrm{M} \mathrm{Ag} /$ $\mathrm{AgCl}$.

determine the amount of DNA immobilized. To mimic the situation on ITO surface, the gold crystal was first modified with MPA to obtain a negatively charged surface, to which an avidin layer was then adsorbed by electrostatic adsorption. Like Rusling et al., ${ }^{18}$ we assumed that this surface should be similar to the avidin-coated ITO and would adsorb approximately the same amount of DNA. Using a density of $1.3 \mathrm{~g} / \mathrm{cm}^{3}$ for avidin, ${ }^{19}$ the thickness of the protein layer was estimated to be approximately $8 \mathrm{~nm}$, which suggests submonolayer coverage after taking into account the surface roughness of piranha-treated gold. ${ }^{20}$

After deposition of CT-DNA from a $200 \mu \mathrm{g} / \mathrm{mL}$ solution on avidin-coated surface, the QCM frequency shift was in the range of -44 to $-49 \mathrm{~Hz}$. It can be estimated using the Sauerbrey equation that $318 \mathrm{ng} / \mathrm{cm}^{2}$ nucleic acid was immobilized on the avidin-coated gold electrode. ${ }^{21}$ The value is very close to that measured by Rusling et al. on myoglobin-coated surface. ${ }^{18}$ The dependence of QCM frequency change on DNA concentration displayed a plateau when the deposition solution was higher than $200 \mu \mathrm{g} / \mathrm{mL}$, suggesting surface saturation. Therefore, DNA solution of $200 \mu \mathrm{g} / \mathrm{mL}$ was used for deposition in the following experiments.

After a DNA film was assembled and reacted with the highaffinity intercalator Ru-dppz, voltammetric measurement was carried out in a redox-free electrolyte. A range of intercalator concentrations were examined, and the results are shown in Figure 1. At very low concentrations $(0.3 \mu \mathrm{M}$ or less $)$, the voltammetric response was broad and poorly defined. As the concentration was increased to $1 \mu \mathrm{M}$, a well-defined oxidation peak was observed with a potential of $1.2 \mathrm{~V}$. With further increase in concentration, the peak height increased accordingly, with its potential shifted progressively to a lower value (peak 1). More significantly, at high concentrations ( $10 \mu \mathrm{M}$ or higher), an additional oxidation peak emerged (peak 2). Although its current increased with Ru-dppz concentration, the potential remained unchanged at $1.25 \mathrm{~V}$. A control experiment was performed in which an avidin-modified ITO was immersed in the Ru-dppz solution and then rinsed. Voltammetric measurement did not show an appreciable electrochemical current, suggesting that adsorption of the complex to the avidin-modified surface was negligible.

There are two possible reasons we can think of for the appearance of multiple oxidation waves in the voltammogram of Ru-dppz bound to the DNA film: film heterogeneity and electrocatalytic oxidation of DNA bases. The DNA film is most likely nonuniform. It is possible that the Ru-dppz molecules reside in different environments when bound to the film. This would result in multiple oxidation potentials even in the absence 


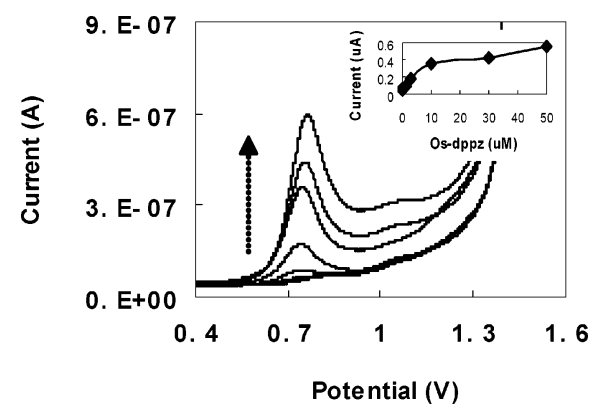

Figure 2. Voltammograms of CT-DNA film electrodes in $20 \mathrm{mM}$ phosphate buffer ( $\mathrm{pH} 7.3)$ after reacting with $0,0.1,0.3,1,3,10,30$, and $50 \mu \mathrm{M} \mathrm{Os}(\mathrm{bpy})_{2}(\mathrm{dppz})$. The arrow indicates increasing concentration. DNA films were deposited from a $0.2 \mathrm{mg} / \mathrm{mL}$ solution. Scan rate: $10 \mathrm{mV} / \mathrm{s}$. Reference: $3 \mathrm{M} \mathrm{Ag} / \mathrm{AgCl}$.

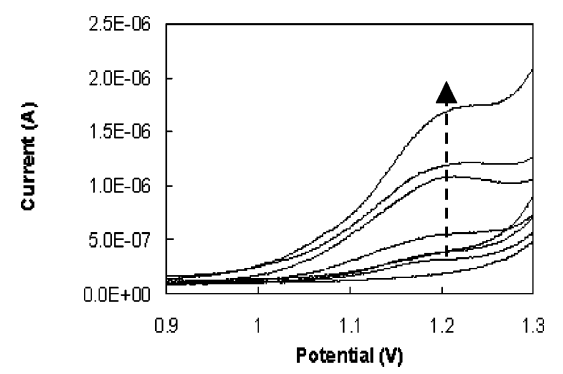

Figure 3. Voltammograms of poly-(AU) film electrodes in $20 \mathrm{mM}$ phosphate buffer ( $\mathrm{pH} 7.3)$ after reacting with $0,0.1,0.3,1,3,10,30$, and $100 \mu \mathrm{M} \mathrm{Ru}(\mathrm{bpy})_{2}(\mathrm{dppz})$. The arrow indicates increasing concentration. Poly-(AU) films were deposited from a $0.2 \mathrm{mg} / \mathrm{mL}$ solution. Scan rate: $10 \mathrm{mV} / \mathrm{s}$. Reference: $3 \mathrm{M} \mathrm{Ag} / \mathrm{AgCl}$.

of electrocatalysis. To probe this possibility, the concentration dependence experiment described above was repeated with Osdppz as the redox probe. The low oxidation potential of the osmium complex $(0.72 \mathrm{~V})$ ensures that it does not electrocatalytically oxidize any DNA bases and thus simplify the situation. ${ }^{4 b}$ As shown in Figure 2, at $1 \mu \mathrm{M}$ or higher concentrations, a welldefined oxidation peak is observed at $0.75 \mathrm{~V}$, obviously due to the electrochemical oxidation of the complex. Contrary to the ruthenium chelate, even at high concentrations where the anodic current started to level off, the peak potential did not change. Also, there was no emergence of additional peaks. The charge estimated from Figure 2 is $24 \mu$ Coulomb $/ \mathrm{cm}^{2}$, corresponding to $2.5 \times 10^{-10} \mathrm{~mol} / \mathrm{cm}^{2}$ Os-dppz. Based on the QCM measurement, the amount of double-stranded DNA (ds-DNA) deposited on the electrode was $5.3 \times 10^{-10} \mathrm{~mol} / \mathrm{cm}^{2}$ base pair. The calculation suggests a binding ratio of two base pairs for each Os-dppz, which is in good agreement with previous study. ${ }^{4 b}$ The titration experiment with Os-dppz proves that the metal complex does not change its redox potential and display multiple peaks simply by binding to DNA film. Since the ligands and coordination geometry of Ru and Os chelates are the same, it can be assumed that they bind with DNA in a similar way.

To provide additional support for the above conclusion, the concentration dependence experiment was carried out with $\mathrm{Ru}-$ dppz on poly-(AU) film. Because poly-(AU) is double-stranded, Ru-dppz can bind to it by intercalation as well as electrostatic attraction. Electrocatalytic oxidation of the bases should be either nonexisting or very slow, since there is no guanine in the film and the oxidation potential of adenine and uracil is much higher than Ru-dppz. ${ }^{22}$ As shown in Figure 3, only one oxidation peak at about $1.2 \mathrm{~V}$ was observed for Ru-dppz bound to the poly(AU) film, the magnitude of which increased at higher Ru-dppz concentrations. This result suggests that the appearance of peak 1 in Figure 1 requires participation from guanine.

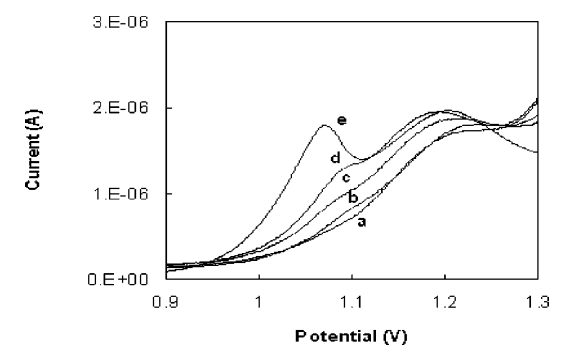

Figure 4. Voltammograms of CT-DNA/poly-(AU) film electrodes in $20 \mathrm{mM}$ phosphate buffer (pH 7.3) after reacting with $100 \mu \mathrm{M} \mathrm{Ru}-$ (bpy) ${ }_{2}(\mathrm{dppz}$ ). Nucleic acid films were deposited from a $0.2 \mathrm{mg} / \mathrm{mL}$ solution containing (a) 0, (b) 10, (c) 30, (d) 50, and (e) $100 \%$ CTDNA. Scan rate: $10 \mathrm{mV} / \mathrm{s}$. Reference: $3 \mathrm{M} \mathrm{Ag} / \mathrm{AgCl}$.

We now consider the possibility that Ru-dppz undergoes redox reaction with guanine bases in DNA, and by doing so shifts its apparent oxidation potential. To probe the role of guanine directly, nucleic acid films with varying amounts of guanine bases were assembled on avidin-coated ITO electrodes. This was done by preparing films from a mixed solution of CT-DNA and poly-(AU) at different ratios but all with a total concentration of $0.2 \mathrm{mg} / \mathrm{mL}$. The hybrid film was reacted with $100 \mu \mathrm{M}$ Ru-dppz, washed, and then measured by voltammetry. As discussed above for Figure 3, the guanine-free (100\% poly$(\mathrm{AU}))$ film exhibited only one oxidation peak at $1.22 \mathrm{~V}$. When $10 \%$ CT-DNA was mixed with poly-(AU), a small shoulder appeared at $1.1 \mathrm{~V}$ in the voltmmogram in addition to the main peak at $1.22 \mathrm{~V}$. The shoulder grew rapidly with CT-DNA concentration in the film, accompanied by a cathodic shift of its potential. The magnitude and potential of the main peak also changed with CT-DNA concentration, but not as large as the shoulder. When the film was $100 \%$ CT-DNA, the shoulder became peak-shaped (peak 1) and as large as the other one (peak 2 ). The results in Figure 4 show explicitly that the appearance of peak 1 is due to guanine oxidation.

Although there is no theoretical treatment in the literature of an $\mathrm{EC}^{\prime}$ mechanism in which both the catalyst and the substrate are immobilized on an electrode surface, several models have been developed for systems composed of immobilized catalyst and diffusive substrate. ${ }^{23-25}$ In particular, Xie and Anson have calculated the cyclic voltammetric response as a function of increasing catalyst coverage at fixed substrate concentration, and found that the peak potential shifts negatively as the catalyst coverage is increased. ${ }^{23 a}$ In our experiments in Figure 1, the surface concentration of the substrate (guanine) was unchanged, and that of the electrocatalyst (Ru-dppz) was increased. Therefore, a negative shift of the voltammetric peak potential is expected for the same reason, i.e., substrate depletion at relatively high catalyst concentrations.

Several previous studies ${ }^{4 c, 26,27}$ have investigated oxidation of guanines in DNA films catalyzed by surface-attached ruthenium tris(bipyridine). For the electrostatic DNA binder, the catalytic peak usually appears at its oxidation potential. There is no preor post-peak present (although there is an exception when the solvent is poly(ethylene glycol $)^{28}$ ). However, when a DNA intercalator is used (as is the case in our study), two catalytic peaks are observed: a regular peak and a pre-peak, with the catalytic efficiency of the latter being larger than that of the former. For the same type of molecules to exhibit different catalytic activities, they must be binding to DNA in different modes. At least two binding modes can be hypothesized for Ru-dppz. In one mode (mode 1), the metal chelate is able to oxidize the nucleotide bases at a fast rate, whereas in the other mode (mode 2) the rate is slow. Ru-dppz has been reported to 


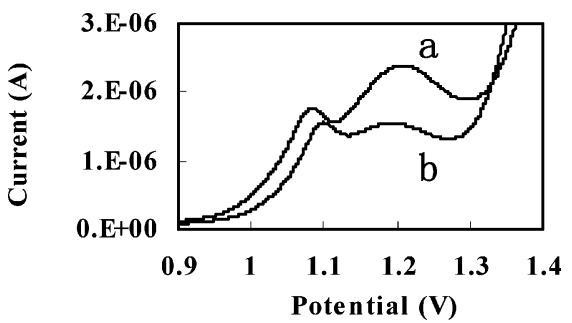

Figure 5. Voltammograms of CT-DNA film electrodes in $20 \mathrm{mM}$ phosphate buffer (pH 7.3) after reacting with (a) $300 \mu \mathrm{M} \mathrm{Ru}(\mathrm{bpy})_{2} \mathrm{dppz}$ and (b) $300 \mu \mathrm{M} \mathrm{Ru}(\mathrm{bpy})_{2}(\mathrm{dppz})$, then $3 \mathrm{mM} \mathrm{MgCl} 2$. Both electrodes were washed with $20 \mathrm{mM}$ phosphate after the reaction. Scan rate: 10 $\mathrm{mV} / \mathrm{s}$. Reference: $3 \mathrm{M} \mathrm{Ag} / \mathrm{AgCl}$.

bind with ds-DNA by intercalation as well as electrostatic interaction. ${ }^{2}$ In ds-DNA, the nucleotide bases are located inside the helical structure and are not easily accessible for redox reaction. ${ }^{4 a}$ Intercalation brings the metal chelate into close contact with the bases, thus shortening the distance of electron transfer reaction. It is therefore proposed that mode 1 is intercalation and mode 2 is nonintercalative. To investigate the nature of mode 2 , the following experiment was carried out. After a ds-DNA film was reacted with Ru-dppz, it was further treated in $\mathrm{Mg}^{2+}$. Magnesium cation is known to bind to DNA phosphate groups by ionic interaction. Treatment with $\mathrm{Mg}^{2+}$ would displace the Ru complex bound electrostatically to DNA. As depicted in Figure 5, although the magnitude of peak 1 did not change much after $\mathrm{Mg}^{2+}$ treatment, that of peak 2 decreased significantly (300 $\mu \mathrm{M}$ Ru-dppz was used in this particular experiment to make the effect more explicit). The result indicates that mode 2 is predominantly electrostatic interaction. Biexponential decay of fluorescence emission from Ru-dppz bound to DNA in solution was observed by Friedman et al., and was rationalized by two binding modes-one an intercalative mode and the other a surface-binding mode. ${ }^{29}$ Fluorescence of the same complex bound to DNA films on ITO was not observed, most likely due to interfacial electron transfer quenching of the excited state. ${ }^{30}$ We also attempted to independently verify the two binding modes by measuring the absorbance of Ru-dppz/ DNA film. Unfortunately, due to the small change of absorbance in the visible region (about $10 \%$ in the solution phase) ${ }^{31}$ and the inherently lower reproducibility of the film sample (about $10-15 \%$ variation), no definitive results were obtained. The fact that the multiple binding modes of the metal chelate with different catalytic reactivities were observed explicitly by DNA film voltammetry demonstrates the unique strength of this method.

\section{Conclusions}

DNA film voltammetry of Ru(bpy $)_{2}(\mathrm{dppz})^{2+}$ displayed two distinctive oxidation peaks which were related by experimental evidence to the oxidation of DNA bases catalyzed by the metal complex at two different rates. A two binding mode hypothesis, one intercalative and the other electrostatic, was proposed to explain the different redox reactivities of the metal complex. This work demonstrates that DNA film voltammetry is a simple, rapid, but informative method for the study of DNA recognition and redox reactivity of redox molecules.

Acknowledgment. This work was supported by a startup fund provided by the Chinese Academy of Sciences. Os(bpy $)_{2}$ dppz was a kind gift from Dominic Hull in Prof. H.
Holden Thorp's group at the University of North Carolina. We thank the reviewer for very constructive comments and helpful suggestions.

\section{References and Notes}

(1) Dervan, P. B. Bioorg. Med. Chem. 2001, 9, 2215. 2777.

(2) Erkkila, K. E.; Odom, D. T.; Barton, J. K. Chem. Rev. 1999, 99,

(3) (a) Carter, M. T.; Bard, A. J. J. Am. Chem. Soc. 1987, 109, 7528. (b) Carter, M. T.; Rodriguez, M.; Bard, A. J. J. Am. Chem. Soc. 1989, 111, 8901.

(4) (a) Johnston, D. H.; Glasgow, K. C.; Thorp, H. H. J. Am. Chem. Soc. 1995, 117, 8933. (b) Welch, T. W.; Corbett, A. H.; Thorp, H. H. J. Phys. Chem. 1995, 99, 11757. (c) Ontko, A. C.; Armistead, P. M.; Kircus, S. R.; Thorp, H. H. Inorg. Chem. 1999, 38, 1842.

(5) (a) Kelley, S. O.; Barton, J. K.; Jackson, N. M.; Hill, M. G. Bioconjugate Chem. 1997, 8, 31. (b) Kelley, S. O.; Jackson, N. M.; Hill, M. G.; Barton, J. K. Angew. Chem., Int. Ed. 1999, 38, 941.

(6) (a) Steel, A. B.; Herne, T. M.; Tarlov, M. J. Anal. Chem. 1998, 70, 4670. (b) Steel, A. B.; Herne, T. M.; Tarlov, M. J. Bioconjugate Chem. 1999, 10, 419.

(7) (a) Pang, D.-W.; Abruna, H. D. Anal. Chem. 1998, 70, 3162. (b) Pang, D.-W.; Abruna, H. D. Anal. Chem. 2000, 72, 4700.

(8) Yu, H.-Z.; Luo, C.-Y.; Sankar, C. G.; Sen, D. Anal. Chem. 2003, 75, 3902.

(9) Liu, B.; Bard, A. J.; Li, C. Z.; Kraatz, H. B. J. Phys. Chem. B 2005, 109, 5193.

(10) (a) Palecek, E. Talanta 2002, 56, 809. (b) Wang, J. Anal. Chim. Acta 2002, 469, 63. (c) Drummond, T. G..; Hill, M. G.; Barton, J. K. Nat. Biotechnol. 2003, 21, 1192. (d) de-los-Santos-Alvarez, P.; Lobo-Castanon, M. J.; Miranda-Ordieres, A. J.; Tunon-Blanco, P. Anal. Bioanal. Chem. 2004, 378, 104. (e) Lucarelli, F.; Marrazza, G..; Turner, A. P. F.; Mascini, M. Biosens. Bioelectron. 2004, 19, 515.

(11) Maruyama, K.; Mishima, Y.; Minagawa, K.; Motonaka, J. Anal. Chem. 2002, 74, 3698.

(12) Wong, E. L. S.; Gooding, J. J. Anal. Chem. 2003, 75, 3845.

(13) del Pozo, M. V.; Alonso, C.; Pariente, F.; Lorenzo, E. Anal. Chem. 2005, 77, 2550 .

(14) Tansil, N. C.; Xie, H.; Xie, F.; Gao, Z. Anal. Chem. 2005, 77, 126.

(15) Armstrong, F. A.; Heering, H. A.; Hirst, J. Chem. Soc. Rev. 1997, $26,169$.

(16) Musumeci, S.; Rizzarelli, E.; Fragala, I.; Sammartano, S.; Bonomo, R. P. Inorg. Chim. Acta 1973, 7, 660.

(17) Edmond, A.; Abdulrazzak, H. J. Chem. Soc., Dalton Trans. 1990 , 1841 .

(18) Lvov, Y. M.; Lu, Z.; Schenkman, J. B.; Zu, X.; Rusling, J. F. J. Am. Chem. Soc. 1998, 120, 4073.

(19) Lovov, Y.; Ariga, K.; Ichinose, I.; Kunitake, T. J. Am. Chem. Soc. 1995, 117, 6117.

(20) Choi, S.-J.; Choi, B.-G.; Park, S.-M. Anal. Chem. 2002, 74, 1998.

(21) Wei, M.-Y.; Guo, L.-H.; Chen, H. Microchim. Acta, published online 2006, http://dx.doi.org/10.1007/s00604-006-0596-8.

(22) Fojta, M. Electroanalysis 2002, 14, 1449.

(23) (a) Xie, Y.; Anson, F. C. J. Electroanal. Chem. 1995, 384, 145. (a) Xie, Y.; Anson, F. C. J. Electroanal. Chem. 1995, 396, 441. (c) Xie, Y.; Anson, F. C. J. Electroanal. Chem. 1996, 404, 209.

(24) (a) Andrieux, C. P.; Blocman, C.; Dumas-Bouchiat, J. M.; M'Halla, F.; Savéant, J. M. J. Electroanal. Chem. 1980, 113, 19. (b) Bourdillon, C.; Demaille, C.; Moiroux, J.; Saveant, J. M. Acc. Chem. Res. 1996, $29,529$.

(25) Heering, H. A.; Hirst, J.; Armstrong, F. A. J. Phys. Chem. B 1998, 102, 6889.

(26) Mugweru, A.; Rusling, J. F. Anal. Chem. 2002, 74, 4044.

(27) Rusling, J. F. Biosens. Bioelectron. 2004, 20, 1022.

(28) Szalai, V. A.; Jayawickramarajah, J.; Thorp, H. H. J. Phys. Chem. B 2002, 106, 709 .

(29) Friedman, A. E.; Chambron, J.-C.; Sauvage, J.-P.; Turro, N. J.; Barton, J. K. J. Am. Chem. Soc. 1990, 112, 4960.

(30) Guo, L.-H.; Mukamel, S.; McLendon, G. J. Am. Chem. Soc. 1995, 117, 546.

(31) Ling, L.-S.; He, Z.-K.; Song, G.-W.; Han, H.-Y.; Zhang, H.-S.; Zeng, Y.-E. Microchim. Acta 2000, 134, 57. 